\title{
The risk-management theory in modern economic conditions
}

\author{
Ajdar Ajupov ${ }^{1, *}$, Anna Sherstobitova ${ }^{2}$, Svetlana Syrotiuk ${ }^{2}$, and Alexey Karataev ${ }^{3}$ \\ ${ }^{1}$ Kazan Federal University, Institute of Management, Economics and Finance, 420008, Kazan, Russia \\ ${ }^{2}$ Togliatti State University, 445667, Togliatti, Russia \\ ${ }^{3}$ Surgut State University, 628400, Surgut, Russia
}

\begin{abstract}
The article reveals features of risk-management theory in environmental enterprise. Risk management is considered according to the system approach. The interaction of the managed and managing subsystems and their cooperation with the external environment are being studied and analyzed. The object of management is a risky investment in the implementation of economic relations between economic entities. The subject of management is a team of specialists. They provide purposeful action on the controlled objects through various techniques and methods of financial risk management.
\end{abstract}

\section{Introduction}

The theory of risk-management is based on three basic concepts: utility, regression and diversification. Utility method was first proposed in 1738 by Daniel Bernoulli, resulting in the decision making process where people have to pay more attention to the size of the effects of different outcomes. It is described in the works of M. Bulmer and F. Galton [1].

The use of regression began at the end of the XIX century. Later it was proved that the rule of regression functions in a variety of situations ranging from the calculation of the probability of risks, and ending with the prediction of business cycle fluctuations.

Mathematical justification of the strategy of diversification of the investment portfolio has been offered by H. Markowitz in 1952 [2]. He has shown the intelligent allocation of investments to minimize the deviation from the expected rate of return.

Currently, with the organization of the risk management system in the sphere of professional activity continue to engage experts in various fields and the process is described by Hubbard Douglas [3], Mark Dorfman [4], Alexander Budzier and Flyvbjerg, B. [5] and others.

The aim of the article is to reveal the progress of risk management in various aspects in environmental enterprise. The model of financial risk management in the implementation of the state program is shown.

An algorithm for the management of financial flows under the state program. Displaying the further development of the theoretical foundations of utility theory was developed by Daniel Bernoulli in the annotation to the implementation of the risk assessment of the individual components of the state program ISO-Standard [6-8].

\footnotetext{
* Corresponding author: Ajdar.Ajupov@kpfu.ru
} 
The results of the risk assessment and management can be seen in the implementation of innovative projects. The object of the study was the company's IT services work to resolve the problems of high-tech state orders.

Risk management is the process of adaptation and implementation of administrative decisions aimed at reducing the possibility of adverse effects. Risk is a financial category, so all the situations where there are the risks should be considered from a financial point of view.

\section{Theory}

The State Program "The developing financial and insurance markets and setting up the International Financial centre" is developed to achieve the increasing the competitiveness of National Economy. It can be achieved through the increasing the effectiveness of monitoring in financial market. It is planned for the period from 2013-2020 and supported by state investments. It is the Finance Ministry that is the executive and the Ministry of Economic development of Russia is the main participant of the program.

Let's make an analysis of the financial market in Russia.

The Russian financial market is a complex diversified, multi-level professional system. This is an emerging market. It is characterized by high rates of growth dynamics and the operating capacity and is characterized by a high level of risk. The existing complex problems of the financial market in the country opposes the development of the economy and improve the investment climate. The Table 1 shows the main risks of the implementation of decisions of the state program.

Table 1. The risks of State Program Implementation.

\begin{tabular}{|l|l|}
\hline Type of risk & Influence of risk \\
\hline Microeconomic & $\begin{array}{l}\text { The decrease of National Economy development } \\
\text { The decreasing of investment activity } \\
\text { Inflation rise } \\
\text { Crisis and conflict situations in financial system }\end{array}$ \\
\hline Legal risks & $\begin{array}{l}\text { Financial laws don't correspond financial market development } \\
\text { The assessment criteria is not available } \\
\text { Legal criteria is not available }\end{array}$ \\
\hline Managerial risks & $\begin{array}{l}\text { The possibility of gap between the activity of legislative branch and } \\
\text { the activity of executive branch. } \\
\text { The possibility of gap between the activity of an executive and the } \\
\text { participants. }\end{array}$ \\
\hline Regional risks & $\begin{array}{l}\text { The possibility of gaps between different regions due to lack of } \\
\text { financial support and high level of centralization of financial services }\end{array}$ \\
\hline
\end{tabular}

This approach will allow for the development of subsequent programs of measures to reduce the risk to a level of quality with the new acquired knowledge of the risk. The results of each stage are the initial data for subsequent phases, forming a decision-making system with feedback. This system provides the most efficient achievement of the objectives, because knowledge is obtained at each stage and it allows you to adjust not only the methods of exposure to risk, but also the very purposes of risk management.

Let's consider the steps of the risk management of financial flows in organization, according.

The first step in the organization of risk management is to identify the funding for the purpose of risk and target risk capital investments. The Stage of setting goals of risk management is characterized by the use of methods of analysis and forecasting of economic conditions, identifying the opportunities and needs of the financial instruments use. 
At the stage of the risk analysis, methods of qualitative and quantitative analysis are used. The purpose of evaluation is to determine the acceptable level of risk. In implementing the State program of the acceptability of the risk can be determined based on the size of budgeting.

In the third stage, there is a comparison of both the effectiveness and influence of selected methods on the risk: risk reduction, risk-taking over, transferring part or all of the risk to third parties, which makes a final decision on the choice of an optimal set.

At the final stage of risk management, the cost of the risk is estimated and a package of measures to reduce risks is made. It specifies the intended impact of their implementation, the timing of implementation, sources of funding and the persons responsible for the implementation of this program.

For example, the amount of necessary financial resources to implement the program «Control and supervision in the financial markets and insurance activities» at the expense of the federal budget and is provided as part of the Federal Service for Financial Markets in the following budgetary allocations is considered.

An important step in the organization of risk management is to control the implementation of the planned program, the analysis and evaluation of the implementation of the selected option risk solutions. It is recommended to accumulate all the information about errors and shortcomings of program development that emerged in the course of its implementation. We consider the activities of the State Program "Development of financial and insurance markets, the creation of an international financial center" as innovation. We show one possible implementation of a risk management program among financial market participants.

Innovative activity is characterized by uncertainty, which is understood as the lack of representation of the environment in which these activities will be carried out. The uncertainty associated with incomplete or inaccurate information about the totality of the factors and their dynamics in the period of innovation and their impact on the final results of innovation processes.

All of the various risks associated with the introduction and implementation of government programs, combine:

1) The relationship with risk of future losses in profit, income, total desired effect;

2) The risk of dependence on the uncertainty of future conditions for the implementation of innovation;

3) Impact on the qualitative and quantitative characteristics of the aggregate risk management decisions;

4) The impact of innovation on the market risks of the competitive environment.

According to the utility function the favorable (chance) and poor (risk) the outcome of uncertainty can be estimated. A. Marshall was the first, who considered the utility theory in economics [9]. Nowadays his ideas are developed by Bordley, R. and M. LiCalzi [10].

Chances and risks form a complete group of events: positive and negative. Let them respectively as the "P" and "Q". The sum of the probabilities of favorable $(\mathrm{P})$ and unfavorable outcome $(\mathrm{Q})$ is equal to one.

Note that chance as an economic category, is a set of temporary factors and conditions for the effective flow of innovation and its management. In managing the risks should be evaluated not only by their spread, but the combination of the risks and chances at every stage of the innovation process. Also it should be noted that some of the opportunities and risks can be realized mainly on the final stage of the innovation project.

To construct a model of risk management the sophisticated tool system approach «method of structural analysis and synthesis» is used. As a result, the use structure of causality, which reflects aspects of the interaction between the components of a complex system, is to achieve the target parameters has been built. Interactions are shown in the form of power indices $\left(R_{\mathrm{i}}\right)$, reflecting the attitude of emerging causality. They may be structurally 
arranged in a series or parallel or a combination of block structure consisting of $\mathrm{n}$ blocks, which may describe the mathematical law that characterizes the dynamics of the system.

Model risk management takes into account the expected costs associated with risk management. If the probability of occurring costs $(\mathrm{Q}(\Sigma \mathrm{Ri} \geq 1))$ increases monotonically with time, and hence the losses arising from the accumulated risk will vary in proportion to the probability of Q ( $t$ ) of the whole system and its elements according to the expression:

$$
Z\left(t ; Z_{i}\right)=\sum_{a} Q_{a}(t) \cdot Z_{a}+\sum_{b} Q_{b}(t) \cdot Z_{b}+\sum_{c} Q_{c}(t) \cdot Z_{c}+\sum_{d} Q_{d}(t) \cdot Z_{d}
$$

where:

$\mathrm{Z}(\mathrm{t}, \mathrm{Zi}))$ - the total loss of the potential risks;

$\mathrm{a}, \mathrm{b}, \mathrm{c}, \mathrm{d}$ - Symbols of the elements that make up the structure, which reflects the causal relationship of risk.

$\mathrm{Q}_{\mathrm{a}}(\mathrm{t}) ; \mathrm{Q}_{\mathrm{b}}(\mathrm{t}) ; \mathrm{Q}_{\mathrm{c}}(\mathrm{t}) ; \mathrm{Q}_{\mathrm{d}}(\mathrm{t})$ - The probability of recovery of the costs of operations after the occurrence of certain risk situation;

$\mathrm{Z}_{\mathrm{i}}$ - the total cost for the $i$-th risk situation arising, for the elements with indices $(\mathrm{a}, \mathrm{b}, \mathrm{c}$, d) of the system.

$\mathrm{Z}\left(\mathrm{t}, \mathrm{Z}_{\mathrm{i}}\right)$ - a function of the growth of total costs to eliminate the impact of risk situations for the last period time $(t)$ of the current operation.

The model algorithm is projected. It consists of four interrelated steps. The algorithm ends with the construction of a strategy to reduce risks. In the development of algorithms and models used regulations recommended by ISO: ISO Guide 73 "Risk management. Glossary" and ISO 31000 "Risk management - Principles and guidelines for implementation" [6, 7].

Table 2 presents the algorithm for Risk Management of innovative activity is shown in.

Table 2. Algorithm for Risk Management of innovative activity.

\begin{tabular}{|c|c|c|}
\hline № & Stage name & Result \\
\hline 1 & Uncertainty analysis & 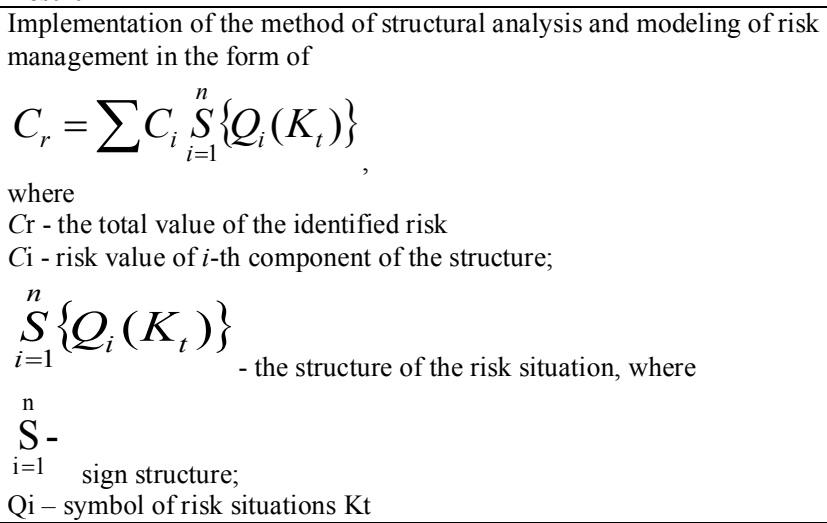 \\
\hline 2 & $\begin{array}{l}\text { Risk identification in } \\
\text { accordance with the } \\
\text { classification of the } \\
\text { existing risks in the } \\
\text { knowledge base }\end{array}$ & $\begin{array}{l}\text { It revealed a set of potentially unwanted factors and formed a set of } \\
\text { qualitative and quantitative characteristics for each of the critical areas of } \\
\text { risk. We analyze the possible corrective action }\end{array}$ \\
\hline 3 & $\begin{array}{ll}\text { Quantitative } & \text { Risk } \\
\text { Assessment } & \end{array}$ & $\begin{array}{l}\text { On the basis of the implementation of the structural analysis performed } \\
\text { quantitative risk assessment, which resulted in the synthesized based on } \\
\text { the methods of synthesis of the structural model of risk management. This } \\
\text { performs sensitivity analysis }\end{array}$ \\
\hline 4 & $\begin{array}{l}\text { Localization strategy of } \\
\text { innovation risk }\end{array}$ & The technique of gradual localization of the risk is formed \\
\hline
\end{tabular}


Sources of risk most likely to occur in the interaction of the organization's personnel, so the human factor is an important parameter to be considered in the risk assessment and management. This feature is indicated by Daniele Trevisani [11].

Glukhova reveals the importance of risk calculations and management in the implementation of innovative projects [12]. The following section is devoted to the risk management on the example of the IT companies is considered.

\section{Results}

We consider the activities of IT companies in the Samara region. The feature of their work is that they perform work on government contracts. In this case, the risk is always present in the amount of $10 \%$.

This type of risk is classified as financial risk. It occurs initially when applying for the solution of problems of the state order. Firstly, you have to pay 10 percent of the project cost for possibility of participation in the tender. In case of refusal of the application on the execution of works, the amount of money will be lost [13].

The risk management decided to allocate several key steps:

1. Risk identification and assessment of refusal possibility and its implementation, the scale of the consequences and determination of the maximum-possible loss;

2. Choice of methods and management tools of identified risks;

3. The development of the risk strategy in order to reduce the probability of the risk and minimize the possible negative consequences;

4. Implementation of the risk strategy;

5. Evaluation of progress and adjusting risk strategy.

A key step in risk management is considered the step of selecting the methods and tools of risk management [14].

Figure 1 presents the analysis of risk situations in the high-tech projects has shown that most often occur following types of risk.

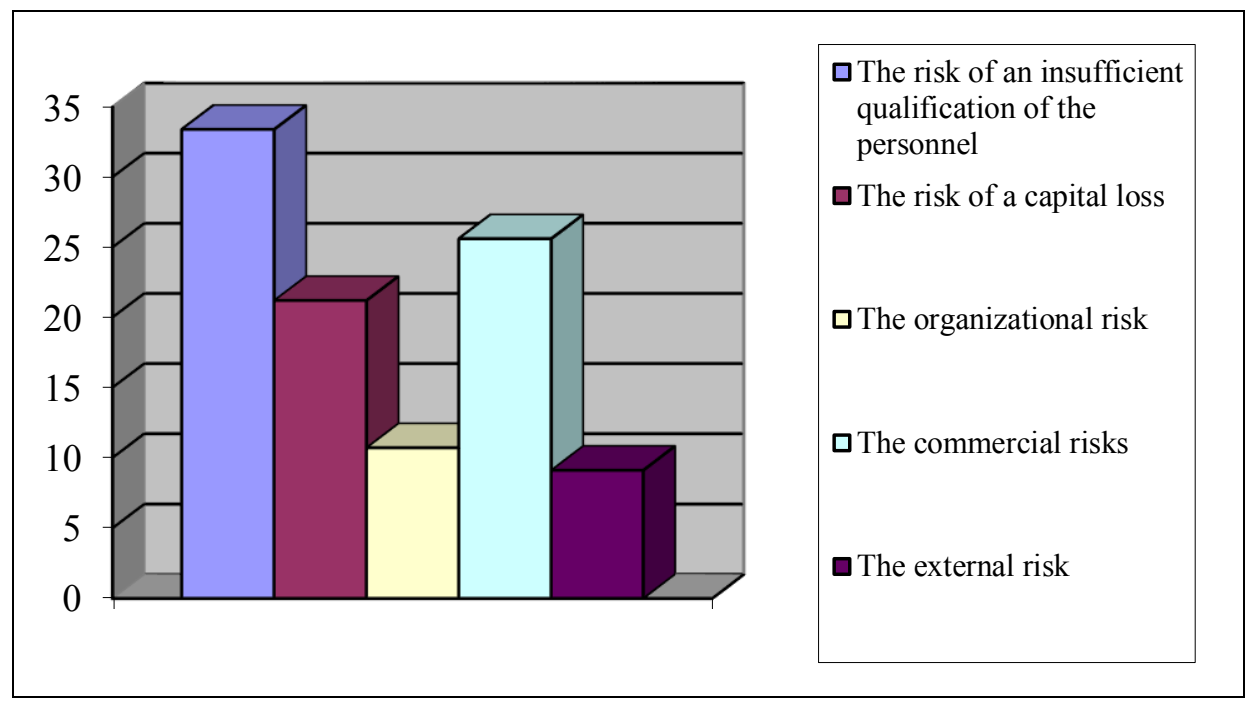

Fig. 1. Risk analysis of innovative projects.

The risk management includes the following activities: 
The first, is a planning the risk management in the particular project. Plans should include the tasks, time realization, and the responsibilities of personnel, activities and budget. The second is an assigning a risk officer - a team member or a project manager who is responsible for foreseeing potential project problems. After that, is a maintaining the risk database for every project.

Each risk should have the following attributes: opening date, title, short description, probability and importance. The creating the risk reporting is a next stage. After that we must consider a preparing mitigation plans for risks that are chosen to be mitigated. The analysis of the effectiveness of decisions and proofreading the risk management purposes is a next stage. And the analysis of planned and of mitigation activities and the assessment of effectiveness of efforts spent for the risk management is a last stage. Nowadays the activity of IT-companies is dealt in the following directions, consider on Figure 2.

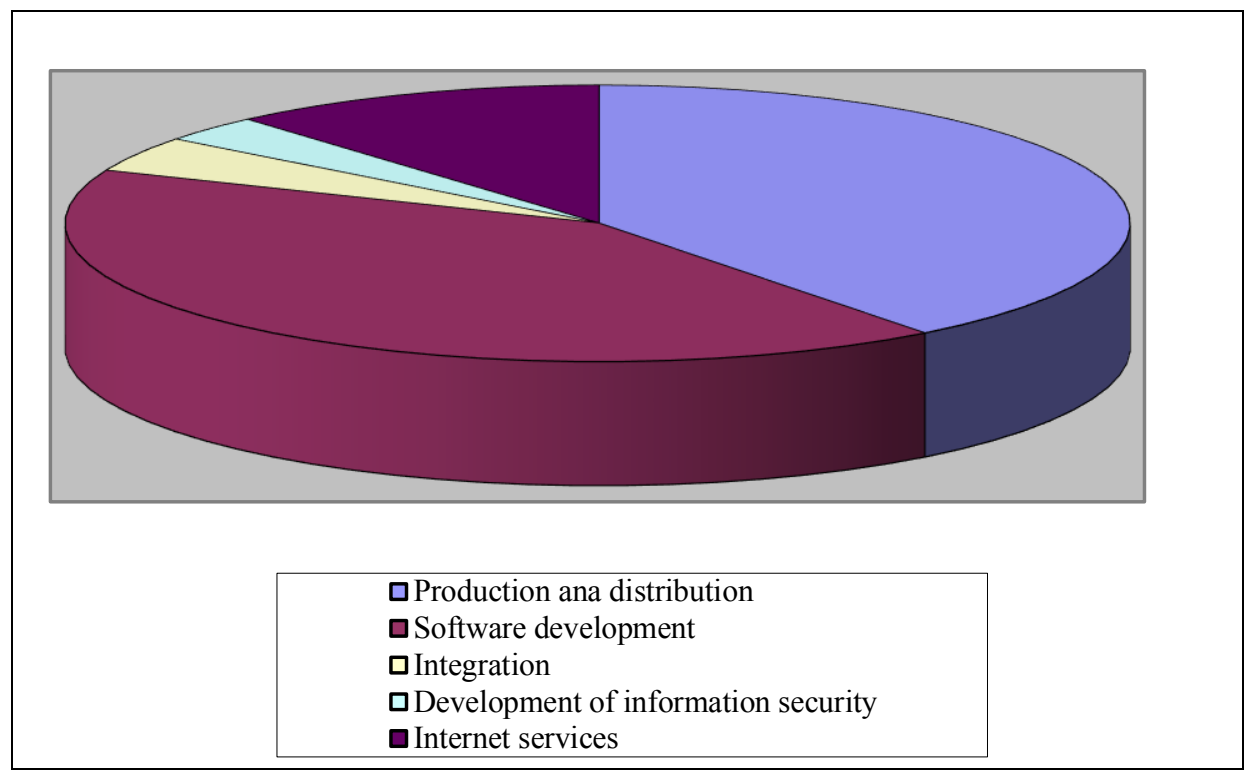

Fig. 2. The activities of IT - company in $2016, \%$.

The empirical scale of possible risks in stages of IT companies you can see in the table 3 . As can be seen from the table, when applying different types of risk, their grading significantly changing for the worse. The current average level of risk may grow up gradation «high risk». In this case, it requires special tools of financial risk - management, aimed at reducing the level of financial risk.

Table 3. Algorithm for Risk Management of innovative activity.

\begin{tabular}{|l|l|l|l|l|l|}
\hline \multicolumn{1}{|c|}{ Stage } & \multicolumn{1}{|c|}{ Risk } & Risk gradation, \% & Gradation name & \multicolumn{1}{|c|}{ Risk threats } & \multicolumn{1}{c|}{ Risk } \\
\hline $\begin{array}{l}\text { Searching } \\
\text { contracts and } \\
\text { tenders }\end{array}$ & Business risks & 10,3 & Low risks & $\begin{array}{l}\text { Business and innovative } \\
\text { risks }\end{array}$ & Middle risk \\
\hline $\begin{array}{l}\text { Planning and } \\
\text { projecting }\end{array}$ & $\begin{array}{l}\text { Purchasing power of } \\
\text { money }\end{array}$ & 31,4 & Middle & Team leader mistakes & Middle risks \\
\hline $\begin{array}{l}\text { Developing } \\
\text { an auction }\end{array}$ & Organizational risks & 10,0 & $\begin{array}{l}\text { Low risks } \\
\text { money pow risks }\end{array}$ & $\begin{array}{l}\text { Lost profit } \\
\text { Information risks }\end{array}$ & low risks \\
\hline $\begin{array}{l}\text { Performance of a } \\
\text { contract }\end{array}$ & Investments risks & 30,8 & $\begin{array}{l}\text { Postponement of deadline } \\
\text { Parties risks } \\
\text { competence of the } \\
\text { third party }\end{array}$ & High risks \\
\hline $\begin{array}{l}\text { Closing } \\
\text { contract }\end{array}$ & Investments risks & 27,5 & Middle risks & $\begin{array}{l}\text { Purchasing power of } \\
\text { money } \\
\text { Obsolete innovation }\end{array}$ & High risks \\
\hline
\end{tabular}


You can see that we must use effective methods of risk management in economic changing systems.

\section{Conclusions}

The conceptual approaches to risk management for the implementation of the State Program «Development of financial and insurance markets, the creation of an international financial center» for the period 2013-2020 ages have a practical focus and relevance.

The novelty of the proposed approach is reflected in the models and methods of structural analysis and synthesis are able to address the activities of the financial market as a complex system in terms of restrictions.

\section{References}

1. M.F. Bulmer, Pioneer of Heredity and Biometry (The Johns Hopkins University Press, 2003)

2. H.M. Markowitz, Selected Works. World Scientific-Nobel Laureate Series (Hackensack, World Scientific, New Jersey, 2009)

3. D. Hubbard, The Failure of Risk Management: Why It's Broken and How to Fix It. John (Wiley \& Sons, 2009)

4. M. Dorfman, Introduction to Risk Management and Insurance (Prentice Hall. Englewood Cliffs, N.J., 2007)

5. B. Flyvbjerg, A. Budzier, Harvard Business Review 89(9), 601-603 (2011)

6. ISO/IEC Guide 73. Risk management - Vocabulary. International Organization for Standardization (2009)

7. ISO/DIS 31000. Risk management - Principles and guidelines on implementation. International Organization for Standardization (2009)

8. CMU/SEI-93-TR-6 Taxonomy-based risk identification in software industry. Sei.cmu.edu. Retrieved on 2012-04-17.

9. Marshall Principles of Economics (Macmillan, London, 1920)

10. R. Bordley, M. LiCalzi, Decision Analysis with Targets instead of Utilities. Decisions in Economics and Finance (2000)

11. D. Trevisani, Regie di Cambiamento (The Directions of Change) (Franco Angeli Publisher, Milan, 2007)

12. L. Glukhova, T. Yanitskaya, Entrepreneurship \& Innovation 4(IV), 14 (2012) 